\title{
Expatriação e adaptação de voleibolistas ao novo contexto social
}

https://doi.org/10.11606/issn.1981-4690.v35i3p27-41

\section{Resumo}

O objetivo do presente manuscrito foi analisar a adaptação dos atletas de Voleibol ao novo contexto social, após mudarem de equipe e cidade para continuarem a carreira, tanto no contexto internacional, como no nacional. Participaram 68 pessoas (48 atletas e 20 ex-atletas), sendo 43 homens e 25 mulheres, com média de idade de 27,29 anos. Os participantes foram divididos em 2 grupos de investigação: G1 (Atletas Internacionais) e G2 (Atletas Nacionais). Utilizou-se um instrumento com questões estruturadas, as quais poderiam ter respostas abertas ou fechadas com respostas em escala do tipo Likert de 5 pontos. $O$ instrumento utilizado foi desenvolvido e avaliado enquanto evidência de validade via TRI, utilizando-se do ajuste ao modelo de Rasch. No presente manuscrito, apenas as questões pertinentes ao objetivo do manuscrito foram analisadas. Para as análises entre grupos, utilizou-se do teste t para amostras independentes e para análise intragrupo, utilizou-se da frequência absoluta e relativa das respostas, Anova one-way, teste t dependente e Correlação de Pearson. Os resultados, demonstraram que os dois grupos apresentaram boa adaptação ao novo contexto social, muito influenciados pela facilidade dos serviços oferecidos pelas cidades e pela não discriminação. Além disso, os participantes dos dois grupos conseguiram constituir novas amizades, o que facilitou seu convívio no novo contexto social, passeios e relações extra clube. Diante de tais resultados, podese concluir que os participantes desse estudo demonstraram recursos pessoais adequados para adaptação, frente as mudanças de contexto, muito possivelmente, por terem utilizado estratégias de coping para esse enfrentamento social.

Palavras-chave: Psicologia do Esporte; Expatriação; Voleibol; Contexto Social; Adaptação.

\section{Introdução}

A expatriação é um instrumento de controle utilizado desde o início das civilizaçôes. Ela pode ser observada desde a Roma antiga, passando pelo período das grandes navegaçóes, onde os europeus promoveram um movimento de expansão do comércio internacional ${ }^{1}$ e chegando nos dias de hoje, em que a expatriação é percebida como o envio de um trabalhador para um país estrangeiro, numa ocupação de gestáo ${ }^{2}$. Certo ${ }^{3}$ define expatriado como um membro de uma organização que vive e trabalha em um país, no qual ele não tem cidadania.
Em outras palavras, expatriados são empregados que as empresas enviam para viver e trabalhar em outro país pela empresa ${ }^{4,5}$. ZwIELEWSKI ${ }^{6}$ analisa a expatriação como uma ação de alterar rotinas, costumes valores pessoais e construir uma nova rede de relacionamentos em outro país. Para Machado e Hernandes ${ }^{7}$, expatriação significa residir em país estrangeiro. Entretanto todas as definiçóes apresentadas remetem ao mundo corporativo, o que não se empregas, muitas das vezes, no ambiente esportivo.
*Universidade Anhembi Morumbi, São Paulo, SP, Brasil.

**Universidade São

Judas Tadeu, São

Paulo, SP, Brasil.

${ }^{* * *}$ Centro Universitário

Padre Anchieta, Jundiaí, SP, Brasil.

****Centro Universitário

Fundação Instituto de

Ensino para Osasco,

Osasco, SP, Brasil.

$* * * * *$ Universidade Estadual Paulista Júlio de Mesquita Filho, Rio Claro, SP, Brasil. 
No âmbito esportivo, entende-se que expatriação pode ser compreendida como a troca de país, pelo atleta, para atuar em outras equipes, dentro do esporte em que atua, ou até em outros esportes ${ }^{8,9}$. PISAni ${ }^{10}$ complementa a explicação, apontando que a expatriaçáo pode ocorrer dentro do país de origem do jogador, assumindo, assim, a mudança de cidade, sendo denominado pela autora como expatriação doméstica. No presente estudo, os conceitos de Brandão et al. ${ }^{8}$, Faggiani et al. ${ }^{9}$ e Pisani ${ }^{10}$ foram assumidos para definição da expatriação no contexto esportivo.

Dessa forma, no âmbito esportivo, a expatriação tem características distintas, pois o atleta não vai para uma filial do clube em que ele atua e sim para um novo clube. Nesse caso, o atleta sai de seu clube de origem e vai para outro clube, assumindo outra cultura e hábitos, que fazem parte do novo clube $e^{11-13}$. Um fator que possa explicar as expatriaçóes no cenário esportivo é puramente econômico. Por exemplo, no Futebol, aproximadamente, $82 \%$ dos atletas profissionais no Brasil ganhavam até dois salários mínimos ${ }^{14}$ e além disso, muitos clubes atrasam salários e prêmios que deveriam ser pagos aos atletas, desmotivando o atleta a permanecer no clube e o levando a procurar "novos ares".

Esse cenário faz com que os atletas tenham a necessidade de constante mudança de equipe, para que possam continuar a desempenhar o esporte, de forma competitiva e profissional ${ }^{15}$, mesmo que essa mudança leve a mudança de nacionalidade ${ }^{14}$. Em alguns casos, a expatriação está relacionada a certo desconforto, insegurança e problemas psicológicos, pois remete a mudança de país, de clube, de cultura ${ }^{8,16,17}$ e a inserção em um novo contexto social é algo que necessita de adaptação e preparação ${ }^{11-13,16,18}$.

Diante disso, o processo de expatriação de atletas necessita de investigação, pois os estudos nessa área são escassos ${ }^{9,11}$ e, além disso, são conduzidos sob a temática Futebol ${ }^{8,9,12,13,19-25}$, sendo pouco tratados com atletas de outras modalidades esportivas ${ }^{26-28}$ e, no caso do Voleibol, temos apenas três estudos, atualmente ${ }^{11,16,29}$, justificando o presente estudo. Além disso, os estudos apontam que a expatriação, no esporte, é algo realizado sem preparação prévia ${ }^{11,24,30}$, o que demonstra a necessidade de estudos para melhorar o planejamento do processo de expatriação e minimizar os problemas psicológicos que o atleta possa ter, assim como contribuir para uma adaptação social favorável.

Perante o exposto, investigar o processo de expatriação no esporte, pode contribuir com a melhoria das habilidades psicológicas dos atletas, em relação a insegurança, mudança de país, cidade e cultura. A investigação no Voleibol contribuirá de forma significativa, pois atletas de Voleibol também participam de expatriaçóes e esse número de atletas de Voleibol cresce a cada ano ${ }^{31}$. Diante disso, o objetivo do presente manuscrito foi analisar a adaptação dos atletas de Voleibol ao novo contexto social, após mudarem de equipe e cidade para continuarem a carreira, tanto no contexto internacional, como no nacional.

\section{Método}

\section{Participantes}

O presente estudo contou com a participação voluntária de atletas e ex-atletas de Voleibola ${ }^{a}$, ou seja, apenas atletas profissionais participaram do estudo, o que foi verificado pela seguinte questão: “Já se profissionalizou?". Se o atleta respondesse negativamente, seria descartado da amostra. Para identificação do ex-atleta, utilizou-se a seguinte questão: "Parou de disputar campeonato?".

Além desses critérios, outro critério para participação foi ter atuado em clubes de cidades diferentes da cidade natal. Por fim, não foi permitida a participação de menores de 18 anos na amostragem. Todos os voluntários que não responderam aos critérios foram descartados do estudo.

Diante de todos os critérios, participaram do estudo 68 pessoas, sendo 43 homens e 25 mulheres. Desse total, 48 ( 35 homens e 13 mulheres) são atletas, e 20 (8 homens e 12 mulheres) ex-atletas, com idade entre 18 e 50 anos (média de 27,29 e desvio padrão de 8,73). Todos os participantes preencheram um Termo de consentimento livre e esclarecido (TCLE) antes de sua participação na pesquisa.

Para formaçáo dos grupos (grupo de expatriados internacionais e grupo de expatriados nacionais), a questão que os direcionava para o seu grupo amostral era a seguinte: “Já defendeu clube de outro país?”. Dessa forma, os participantes foram divididos em 2 grupos: G1 (Atletas Internacionais - 30 participantes) e G2 
(Atletas Nacionais - 38 participantes). Cabe ressaltar que respeitou-se todos os padrões éticos de pesquisas com seres humanos do Conselho Nacional de Saúde (CNS), Resolução 466/12.

Por fim, em relação ao tempo de permanência no novo país, para os atletas do grupo G1, 60\% dos mesmos permaneceu no novo país por mais de 1 ano. Sobre os atletas do G2, observou-se que a maior parte dos participantes são nascidos no Estado de Sáo Paulo e que o grande deslocamento migratório ocorreu na regiáo Sudeste.

\section{Instrumento}

Para esse manuscrito, o instrumento utilizado foi elaborado por Tertuliano ${ }^{11}$. O instrumento foi elaborado em formato de questionário, denominado: "Questionário: O processo de Expatriaçẫo de Jogadores de Voleibol”. Na elaboração utilizou-se de três juízes, sendo 2 psicólogos e 1 educador físico, todos com mais de 10 anos de experiência e com expertise na área. O questionário apresentava 2 partes: a primeira parte apresentava questấo em relação as características gerais do participante, de ordem socioeconômica e de dinâmicas da expatriaçáo dos participantes. Em outras palavras, a primeira parte do instrumento foi a identificaçáo do participante e continha questóes sobre: nome, idade, cidade de nascimento, estado de nascimento, país de nascimento, sexo e estado civil. O intuito foi identificar os sujeitos e permitir a apresentação dos participantes do estudo, a idade, o sexo etc. No presente estudo, utilizou-se apenas as questóes que atendiam o objetivo do mesmo. Dessa forma, questóes que se relacionam a outros objetivos foram descartadas.

A segunda parte do questionário procurou compreender a adaptação do participante ao processo de expatriação, tanto em questóes de motivação ao processo de expatriaçáo, a adaptação do atleta ao novo clube e ao novo contexto social, como em relação a percepção do atleta sobre todo o processo de primeira expatriação (ver instrumento completo em TERTULIANO ${ }^{11}$ ). As questóes foram desenvolvidas com várias categorias de resposta, utilizando-se de escalas do tipo Likert, o que permitiu enfatizar aspectos relevantes da questão e oferecer ao participante uma escolha intermediária de resposta. Assim, as possibilidades de respostas foram: 1 (discordo totalmente), 2 (discordo), 3 (concordo pouco), 4 (concordo) e 5 (concordo totalmente) para as questôes sobre adaptação do participante.

As questóes referentes à percepção da expatriação tiveram as seguintes possibilidades de resposta: 1 (muito ruim), 2 (ruim), 3 (indeciso), 4 (boa) e 5 (muito boa) (as quatro primeiras questóes), ou 1 (discordo totalmente), 2 (discordo), 3 (concordo pouco), 4 (concordo) e 5 (concordo totalmente) (as demais questóes). No presente instrumento existem questóes para os participantes do grupo G1 e G2. No presente estudo, utilizou-se apenas as questóes que tinham em sua estrutura, aspectos que correspondessem ao objetivo do manuscrito, ou seja, o processo de adaptação do atleta ao novo contexto social. Dessa forma, questóes que se relacionam a outros objetivos foram desconsideradas no presente estudo.

Além disso, as questôes que foram utilizadas, neste manuscrito, foram as que, após a análise de Teoria de resposta ao Item (TRI) pelo uso do modelo de Rasch, se encontraram ajustadas ao modelo ${ }^{11}$. Tal procedimento de análise (TRI pelo uso do modelo de Rasch), teve como objetivo, avaliar a unidimensionalidade do instrumento, ou seja, a análise de componentes principais de resíduos pelo modelo de Rasch. A análise foi realizada com todos os itens da segunda parte do instrumento. $\mathrm{O}$ intuito dessa análise foi selecionar os itens que seriam a base para análise de ajuste ao modelo Rasch, ou seja, verificar os itens que se ajustam ao modelo, para depois avaliar a dificuldade e habilidade de itens e pessoas, respectivamente e, com isso, utilizar apenas as questóes ajustadas ao modelo para a fase de análises inferenciais.

Após todas as análises de ajuste dos itens ao modelo Rasch e descarte das questões que não demonstraram ajuste ao modelo de Rasch (as análises avaliaram a carga fatorial dos itens, o outfit, o infit, o mapa de itens e o valor de Theta. Tais análises encontram-se no estudo de Tertuliano ${ }^{11}$ ), restaram as questóes adequadas para prosseguimento das análises inferenciais. Como citado anteriormente, apenas as questóes que atendiam o objetivo do mesmo foram apresentadas no QUADRO 1, ou seja, questóes que se relacionam a outros objetivos foram descartadas do presente estudo.

\section{Procedimentos}

A presente pesquisa respeitou os princípios legais de uma pesquisa que envolve coleta de dados com seres humanos, ou seja, utilizou-se de etapas estabelecidas pela comunidade científica. A pesquisa foi aprovada pelo Comitê de Ética e Pesquisa (CEP) do Instituto de Biociências da Unesp, Campus Rio Claro, sob o número de parecer: 1.537.814. Após o processo de aprovação, foram realizados contatos, via internet (Facebook $^{\oplus}$ e E-mail $)^{32}$, convidados as pessoas para 
QUADRO 1 - Questões utilizadas no presente estudo, após análise de TRI por meio do modelo de Rasch, para os dois grupos ( $\mathrm{G} 1 \mathrm{e} \mathrm{G} 2)$.

A numeração da variável é referente ao seu número de questão no questionário de TERTULIANO ${ }^{11}$.

\begin{tabular}{|l|}
\multicolumn{1}{c|}{ Questóes similares aos dois grupos } \\
\hline 23. A diferença religiosa atrapalhou minha adaptação. \\
48. Fiquei feliz quando soube que trocaria de clube/país. \\
3. A vida social dentro do clube é: \\
4. A vida social fora do clube é: \\
Questóes apenas do grupo G1 \\
\hline 12. A adaptação ao novo país foi fácil. \\
14. A discriminação por ser estrangeiro atrapalhou minha adaptação. \\
46. O convívio com o povo do novo país foi fácil. \\
50. O novo país me proporcionou novos amigos, extra clube. \\
51. O serviço de saúde do novo país me confortou durante minha permanência no novo país. \\
16. Conquistei o respeito que esperava no novo país. \\
17. Conheceu muitos lugares no novo país? \\
Questóes apenas do grupo G2 \\
47. A vida social, estra-clube, foi maior na nova cidade. \\
14. A nova cidade proporcionou novos amigos, extra-clube. \\
14. A discriminação por ser de outra cidade atrapalhou minha adaptação. \\
43a da família na nova cidade atrapalhou minha adaptação.
\end{tabular}

participar do estudo. Nesse convite os possíveis participantes receberam explicaçóes sobre o objetivo do estudo, sendo orientados que poderiam desistir do estudo se desejassem não prosseguir, em qualquer momento da pesquisa.

Após os convites e explicações, foi enviado, por E-mail, o TCLE, para todos que aceitaram participar da pesquisa, os quais leram, preencheram, assinaram e devolveram o TCLE de forma eletrônica (E-mail), respeitando a recomendação do CEP. O instrumento foi disponibilizado para os participantes que devolveram o TCLE, preenchido e assinado, via plataforma eletrônica - Google Formulários ${ }^{\circledR b}$. Após o recebimento do link para acessar o questionário, os participantes responderam as questôes. Como forma de garantir que apenas os participantes que entregaram o TCLE fizessem parte da amostra, comparou-se o nome do participante que entregaram o TCLE com o nome dos participantes que responderam o questionário (Google Formulários ${ }^{\circledR}$ ), descartando as respostas do participante que não entregou o TCLE. Após o término da aplicação do questionário, os dados foram importados do Google
Formulários ${ }^{\oplus}$ para o Microsoft Excel 2016.

\section{Procedimentos de análise}

No presente estudo análises descritivas e inferenciais são apresentadas, pois foi assumida a abordagem quanti-qualitativa para responder aos objetivos do estudo. Como a primeira parte do instrumento tratou-se da caracterização da amostra, não houve necessidade de análises, ou seja, apenas as questóes da segunda parte do instrumento, as quais apresentam-se descritas no QUADRO 1, sofreram análises inferenciais. Para isso, foram conduzidas inferências entre grupos e intragrupo.

De acordo com a teoria do limite central, quanto maior o tamanho da amostra, a distribuição das médias estará mais próxima de uma distribuição normal. Green, SALKInd e AkeY ${ }^{33}$ sugerem que em um grupo amostral com mais de 30 participantes é possível se assumir normalidade e homogeneidade de variância sem o uso de testes para avaliar normalidade e homogeneidade de variância. Diante 
disso, assumiu-se normalidade, utilizando o valor Alfa de 0,05 para diferenças significativas ${ }^{16}$.

Para as análises entre grupos, utilizou-se do teste $t$ para amostras independentes e para análise intragrupo, utilizou-se da frequência absoluta e relativa das respostas, Anova one-way, teste $t$ dependente e Correlação de Pearson. Todas análises foram conduzidas por meio do software IBM SPSS Statistics, versão 20.

\section{Resultados}

Para responder ao objetivo do estudo, as primeiras análises foram conduzidas nas questóes comuns aos dois grupos. Assim, pode-se observar, mediante a capacidade de adaptação do atleta ao novo contexto social, que os atletas dos dois grupos adaptaram-se aos serviços oferecidos na cidade, já que não houve diferença significante entre os grupos. Em relação a diferença religiosa, pode-se observar, também, que não houve diferença significante entre os grupos. Essas informações foram parcialmente confirmadas pela análise inferencial (TABELA 1). Em relação à capacidade de adaptação do atleta frente à nova cidade, o teste $t$ para amostras independentes apresentou diferença significante entre grupos apenas para diferenças religiosas, demonstrando que os participantes do grupo G2 tiveram mais dificuldade de adaptaçáo religiosa.

TABELA 1 - Análise entre grupos sobre adaptação no ambiente externo ao novo clube (n = 68).

\begin{tabular}{|c|c|c|c|c|c|}
\hline Variável & Grupo & $\mathbf{N}$ & Mediana & Moda & $\begin{array}{l}\text { Teste } t \text { para } \\
\text { amostras }\end{array}$ \\
\hline \multirow{2}{*}{$\begin{array}{l}\text { 23. A diferença religiosa } \\
\text { atrapalhou minha adaptação. }\end{array}$} & G1 & 30 & 2,00 & 2 & \multirow{2}{*}{$0,004^{*}$} \\
\hline & G2 & 38 & 2,00 & 1 & \\
\hline \multirow{2}{*}{$\begin{array}{l}\text { 48. Os serviços, como } \\
\text { supermercados, ofereciam } \\
\text { uma variedade de alimentos } \\
\text { para compra, o que facilitou a } \\
\text { adaptação. }\end{array}$} & G1 & 30 & 4,00 & 5 & \multirow[b]{2}{*}{0,397} \\
\hline & G2 & 38 & 4,00 & 4 & \\
\hline
\end{tabular}

$\mathrm{Na}$ comparação intragrupo, conduzida pelo teste $t$ dependente, os resultados apresentaram diferenças significantes para o Grupo G1 $(\mathrm{p}<0,001)$. Essa informação demonstra que os participantes do grupo G1 não apresentaram dificuldade de adaptação aos serviços da cidade, como supermercados, já que apontaram como satisfatório os serviços oferecidos. Além disso, os valores de adaptação frente às diferenças religiosas foram baixos, demonstrando adaptação religiosa satisfatória. Cabe ressaltar que valores próximo de um, no item referente a religião é bom sinal de adaptação. Com o intuito de verificar a correlação entre os itens, utilizou-se do teste de correlação de Pearson. A correlação de
Pearson para o grupo G1 apresentou correlação fraca entre os itens $(r=-0,403, p=0,027)$, ou seja, as questóes religiosas não se relacionam com as questôes de uso dos serviços.

Em relação ao Grupo G2, o teste t dependente, demonstrou diferenças significantes $(\mathrm{p}<0,001)$. Tais resultados demonstram que os participantes do grupo G2 apresentaram adaptação aos serviços da cidade, como supermercados e valores de adaptação as diferenças religiosas baixos, demonstrando satisfatória adaptação. Em relaçáo a correlação entre os itens, a correlação de Pearson apresentou correlação moderada entre os itens $(\mathrm{r}=0,580, \mathrm{p}=0,001)$, ou seja, possivelmente o uso dos serviços da cidade estấo relacionados
Nota. A numeração da variável é referente ao seu número de questão no questionário de TERTULIANO ${ }^{11}$.

* diferença significante entre grupos. 
com a adaptação religiosa. Em outras palavras, é possível dizer que frente a adaptação religiosa, as pessoas saem mais de casa para usarem os serviços oferecidos na cidade.

Concernente à vida social contribuir para o processo de expatriação, dois itens foram analisados, os itens 3 e 4 do questionário supracitado. A análise qualitativa sugere que os grupos tiveram boa vida social, dentro e fora do clube e que o grupo G2 apresentou escores que podem ser interpretados como uma vida social mais ativa fora do clube. Além disso, parece haver uma correlação entre vida social dentro e fora do clube, demonstrando que a vida social dentro do clube contribui para vida social fora do clube. Essas informações foram confirmadas pela análise inferencial (TABELA 2). A análise entre grupos apresentou diferença significante apenas para o convívio fora do clube, indicando que o grupo G2 teve um convívio social fora do clube mais ativo que o grupo G1.

TABELA 2 - Análise entre grupos sobre vida social dentro e fora do clube $(n=68)$.

Nota. A numeração da variável é referente ao seu número de questão no questionário de TERTULIANO"11.

* diferença significante entre grupos.

\begin{tabular}{lccccc}
\hline \multicolumn{1}{c}{ Variável } & Grupo & N & Mediana & Moda & $\begin{array}{c}\text { Teste } \boldsymbol{t} \text { para } \\
\text { amostras }\end{array}$ \\
\hline 3. A vida social dentro do clube é: & G1 & 30 & 4,00 & 4 & 0,244 \\
4. A vida social fora do clube é: & G2 & 38 & 4,00 & 5 & 5 \\
& G1 & 30 & 4,00 & & $0,025^{*}$ \\
\hline
\end{tabular}

Frente as análises intragrupo, os resultados do grupo G1 não apresentaram diferença significante $(\mathrm{p}=0,448)$, ou seja, para esse grupo, os dois convívios (dentro e fora do clube) foram importantes para adaptação, supondose que a vida social fora do clube está relacionada com amigos conquistados no clube. A correlação de Pearson para o grupo G1 apresentou correlação moderada entre os itens $(\mathrm{r}=0,686, \mathrm{p}=0,001)$, demonstrando que a vida social dentro e fora do clube tem moderada relação.

Para o grupo G2, as análises intragrupo apresentaram diferenças significantes ( $\mathrm{p}=0,001)$, ou seja, a vida social fora do clube foi mais ativa que a vida social dentro do clube. A correlaçáo de Pearson para o grupo G2 apresentou correlação moderada $(\mathrm{r}=0,699, \mathrm{p}=0,001)$, demonstrando que a vida social dentro e fora do clube tem moderada relação, corroborando os resultados do grupo G1.

No intuito de explicar melhor o processo de expatriaçáo para cada grupo, algumas questóes foram direcionadas exclusivamente aos grupos. Aliando as variáveis exclusivas com as comuns, buscou-se observar melhor os grupos frente a adaptação ao novo contexto social, fora do clube. Dessa forma, a questão que se relacionava ao contexto social dentro do clube foi descartada dessa análise $\mathrm{Na}$ análise qualitativa, observou-se que os participantes do grupo G1 tiveram uma boa adaptação, pois demonstraram bom convívio com o povo nativo, gostaram dos serviços do país (mercado e saúde), conheceram muitos lugares (passearam pelo país), consideram muito boa a vida social fora do clube, náo tiveram problemas religiosos e nem foram discriminados, ou seja, conseguiram se adaptar de forma favorável ao novo país (TABELA 3).

A análise qualitativa foi confirmada pela análise inferencial com o uso do o teste Anova one-way $[\mathrm{F}(5,35,155,13)=43,21 ; \mathrm{p}<0,001]$, demonstrando que a diferença religiosa e a discriminação foram diferentes dos outros itens $(\mathrm{p}<0,001)$, ou seja, tiveram médias abaixo dos outros itens, sendo que a média baixa é bom sinal, uma vez que quanto mais perto de um é sinal de baixa influência daquele item sobre a adaptação. Esses resultados demonstram que a adaptação ao novo contexto social foi adequada, já que os participantes não apresentaram problemas religiosos ou sofreram discriminação. 
TABELA 3 - Itens relacionados à adaptação do atleta ao novo país, itens comuns e exclusivos do grupo internacional $(\mathrm{G} 1)(\mathrm{n}=30)$.

\begin{tabular}{|c|c|c|c|c|c|c|c|}
\hline Variável & $\begin{array}{c}\text { Discordo } \\
\text { totalmente* }\end{array}$ & Discordo* & $\begin{array}{l}\text { Concordo } \\
\text { pouco* }\end{array}$ & Concordo* & $\begin{array}{r}\text { Concordo } \\
\text { totalmente* }\end{array}$ & Mediana & Moda \\
\hline $\begin{array}{l}23 . \text { A diferença religiosa } \\
\text { atrapalhou minha } \\
\text { adaptação. }\end{array}$ & $13(43,3 \%)$ & $16(53,3 \%)$ & $1(3,3 \%)$ & $0(0 \%)$ & $0(0 \%)$ & 2,00 & 2 \\
\hline $\begin{array}{l}\text { 48. Os serviços, } \\
\text { como supermercados, } \\
\text { ofereciam uma } \\
\text { variedade de alimentos } \\
\text { para compra o que } \\
\text { facilitou à adaptação. }\end{array}$ & $0(0 \%)$ & $4(13,3 \%)$ & $7(23,3 \%)$ & $7(23,3 \%)$ & $12(40 \%)$ & 4,00 & 5 \\
\hline $\begin{array}{l}\text { 12. A adaptação ao } \\
\text { novo país foi fácil. }\end{array}$ & $0(0 \%)$ & $5(16,7 \%)$ & $15(50 \%)$ & $6(20 \%)$ & $4(13,3 \%)$ & 3,00 & 3 \\
\hline $\begin{array}{l}\text { 14. A discriminação } \\
\text { por ser estrangeiro } \\
\text { atrapalhou minha } \\
\text { adaptação. }\end{array}$ & $10(33,3 \%)$ & $13(43,3 \%)$ & $5(16,7 \%)$ & $2(6,7 \%)$ & $0(0 \%)$ & 2,00 & 2 \\
\hline $\begin{array}{l}\text { 46. O convívio com o } \\
\text { povo do novo país foi } \\
\text { fácil. }\end{array}$ & $1(3,3 \%)$ & $3(10 \%)$ & $7(23,3 \%)$ & $10(33,3 \%)$ & $9(30 \%)$ & 4,00 & 4 \\
\hline $\begin{array}{l}\text { 50. O novo país me } \\
\text { proporcionou novos } \\
\text { amigos, extra clube. }\end{array}$ & $0(0 \%)$ & $0(0 \%)$ & $5(16,7 \%)$ & $12(40 \%)$ & $13(43,3 \%)$ & 4,00 & 5 \\
\hline $\begin{array}{l}\text { 51. O serviço de } \\
\text { saúde do novo país } \\
\text { me confortou durante } \\
\text { minha permanência no } \\
\text { novo país. }\end{array}$ & $0(0 \%)$ & $2(6,7 \%)$ & $6(20 \%)$ & $5(16,7 \%)$ & $17(56,7 \%)$ & 5,00 & 5 \\
\hline $\begin{array}{l}16 . \text { Conquistei o } \\
\text { respeito que esperava no } \\
\text { novo país. }\end{array}$ & $2(6,7 \%)$ & $1(3,3 \%)$ & $5(16,7 \%)$ & $4(13,3 \%)$ & $18(60 \%)$ & 5,00 & 5 \\
\hline \multirow[t]{2}{*}{$\begin{array}{l}\text { 17. Conheceu muitos } \\
\text { lugares no novo país? }\end{array}$} & $0(0 \%)$ & $0(0 \%)$ & $0(0 \%)$ & $2(6,7 \%)$ & $28(93,3 \%)$ & 5,00 & 5 \\
\hline & muito ruim* & ruim* & indeciso* & boa* & muito boa* & & \\
\hline $\begin{array}{l}\text { 4. A vida social fora do } \\
\text { clube é: }\end{array}$ & $0(0 \%)$ & $2(6,7 \%)$ & $5(16,7 \%)$ & $11(36,7 \%)$ & $12(40 \%)$ & 4,00 & 5 \\
\hline
\end{tabular}

Nota. A numeração da variável é referente ao seu número de questão no questionário de TERTULIANO ${ }^{11}$.

${ }^{*}$ Apresentação da frequência absoluta e frequência relativa $=$ $\mathrm{FA}(\mathrm{FR})$
Aliado a isso, a questão referente a conhecer muitos lugares no novo país (questão 17 do questionário supracitado), demonstrou diferença significante para os demais itens $(\mathrm{p}<0,001)$. Essa informação demonstra que os participantes conheceram muitos lugares, sugerindo uma adequada adaptação ao novo contexto social, o que lhes permitiu passear pelo novo país, já que não se sentiram discriminados ou apresentaram dificuldades de adaptação religiosa, além de se sentirem confortáveis frente aos serviços de saúde, caso necessitassem do mesmo. Tais achados demonstram um bom indicativo de adaptação ao novo contexto social.

Com o intuito de verificar a correlação entre os itens, utilizou-se do teste de correlaçáo de Pearson. A correlaçáo de Pearson para o grupo G1 apresentou correlação fraca entre os itens $(r<0,510)$, ou seja, a facilidade de adaptação religiosa não tem nenhuma relação com os serviços oferecidos no país, tão pouco com a baixa discriminação ou com o fator de viajarem pelo país para o conhecer.

Referente ao grupo G2, em relação à adaptação do atleta à nova cidade, na análise qualitativa observa-se que os participantes do grupo G2 tiveram uma adaptaçáo adequada, pois tiveram bom convívio com as pessoas da cidade, gostaram dos serviços oferecidos na cidades, conheceram muitos lugares, consideram a vida social fora do clube como regular, não tiveram problemas religiosos e nem foram discriminados. Tais observaçóes sugerem que o grupo G2 conseguiu se adaptar de forma adequada à nova cidade e, além disso, não sentiram falta da família (TABELA 4). 
Nota. A numeração da variável é referente ao seu número de questão no questionário de TERTULIANO"11.

${ }^{*}$ Apresentação da frequência absoluta e frequência relativa $=$ $\mathrm{FA}(\mathrm{FR})$

TABELA 4 - Itens relacionados a adaptação do atleta a nova cidade, itens comuns e exclusivos do grupo nacional (G2) $(\mathrm{n}=38)$.

\begin{tabular}{|c|c|c|c|c|c|c|c|}
\hline Variável & $\begin{array}{c}\text { Discordo } \\
\text { totalmente* }\end{array}$ & Discordo* $^{*}$ & $\begin{array}{l}\text { Concordo } \\
\text { pouco* }\end{array}$ & Concordo* & $\begin{array}{r}\text { Concordo } \\
\text { totalmente* }\end{array}$ & Mediana & Moda \\
\hline $\begin{array}{l}\text { 23. A diferença religiosa } \\
\text { atrapalhou minha } \\
\text { adaptação. }\end{array}$ & $13(34,2 \%)$ & $11(28,9 \%)$ & $7(18,4 \%)$ & $2(5,3 \%)$ & $5(13,2 \%)$ & 2,00 & 1 \\
\hline $\begin{array}{l}\text { 48. Os serviços, } \\
\text { como supermercados, } \\
\text { ofereciam uma } \\
\text { variedade de alimentos } \\
\text { para compra o que } \\
\text { facilitou à adaptaçăo. }\end{array}$ & $3(7,9 \%)$ & $3(7,9 \%)$ & $9(23,7 \%)$ & $12(31,6 \%)$ & $11(28,9 \%)$ & 4,00 & 4 \\
\hline $\begin{array}{l}\text { 12. A adaptaçáo a nova } \\
\text { cidade foi fácil. }\end{array}$ & $5(13,2 \%)$ & $8(21,1 \%)$ & $6(15,8 \%)$ & $10(26,3 \%)$ & $9(23,7 \%)$ & 4,00 & 4 \\
\hline $\begin{array}{l}\text { 14. A discriminaçáo } \\
\text { por ser de outra cidade } \\
\text { atrapalhou minha } \\
\text { adaptaçáo. }\end{array}$ & $18(47,4 \%)$ & $19(50 \%)$ & $0(0 \%)$ & $0(0 \%)$ & $1(2,6 \%)$ & 2,00 & 2 \\
\hline $\begin{array}{l}\text { 18. A falta da família na } \\
\text { nova cidade atrapalhou } \\
\text { minha adaptaçấo. }\end{array}$ & $10(26,3 \%)$ & $10(26,3 \%)$ & $8(21,1 \%)$ & $7(18,4 \%)$ & $3(7,9 \%)$ & 2,00 & 1 \\
\hline $\begin{array}{l}\text { 43. O convívio com o } \\
\text { povo da nova cidade } \\
\text { foi fácil. }\end{array}$ & $6(15,8 \%)$ & $5(13,2 \%)$ & $4(10,5 \%)$ & $11(28,9 \%)$ & $12(31,6 \%)$ & 4,00 & 5 \\
\hline $\begin{array}{l}\text { 44. A vida social, extra } \\
\text { clube, foi maior na nova } \\
\text { cidade. }\end{array}$ & $3(7,9 \%)$ & $5(13,2 \%)$ & $12(31,6 \%)$ & $8(21,1 \%)$ & $10(26,3 \%)$ & 3,00 & 3 \\
\hline $\begin{array}{l}\text { 47. A nova cidade } \\
\text { proporcionou novos } \\
\text { amigos, extra clube. }\end{array}$ & $3(7,9 \%)$ & $3(7,9 \%)$ & $6(15,8 \%)$ & $6(15,8 \%)$ & $20(52,6 \%)$ & 5,00 & 5 \\
\hline
\end{tabular}

A análise qualitativa foi confirmada pela análise inferencial com o uso do o teste Anova one-way $[\mathrm{F}(3,45$, $127,80)=21,13 ; \mathrm{p}<0,001)$, demonstrando que a diferença religiosa, a discriminação e a falta da família apresentaram valores significantemente diferentes dos outros itens $(\mathrm{p}<0,001)$. Tais achados demonstram que não houve discriminação dos moradores da cidade ou atletas do clube com o participante, nem problemas com diferenças religiosas, já que valores baixos desses itens é bom sinal de adaptação.

Além disso, os resultados do item relacionado a falta da família demonstram que a família se fez presente, o que possivelmente pode ser explicado pela proximidade da família, ou por ter ido morar junto, sugerindo que a presença da família auxilia na expatriação, mesmo sendo doméstica (dentro do mesmo país). Outro dado importante é o convívio com as pessoas da nova cidade, os participantes fizeram novas amizades, tiveram convívio social extra clube, o que demonstrou um bom convívio com as pessoas da nova cidade.

Com o intuito de verificar a correlaçáa entre os itens, utilizou-se do teste de correlação de Pearson. A correlação de Pearson para o grupo G2 apresentou correlação forte entre o item 44 e os itens 48 e 43 ( $r>0,712, p<0,001)$, demonstrando que o convívio fora do clube foi favorecido pelos serviços adequados que a cidade oferecia e pela receptividade amistosa que a população teve com o atleta.

Os resultados, em síntese, demonstram que os grupos apresentaram boa adaptaçáo ao novo 
contexto social e que essa boa adaptação foi adquirida devido os novos laços de amizade dentro e fora do clube. Nenhum dos grupos apresentou problemas com discriminação e serviços, como supermercado e saúde. Por fim, apenas o grupo G2 apresentou um valor superior em relação a diferença religiosa, mas que esse valor não foi capaz de atrapalhar a adaptação dos atletas ao novo contexto social, já que os atletas tiveram vida social, extra clube, maior na nova cidade, do que na cidade natal.

\section{Discussão}

De acordo com o objetivo do presente manuscrito, que era analisar a adaptação dos atletas de Voleibol ao novo contexto social, após mudarem de equipe e cidade para continuarem a carreira, tanto no contexto internacional, como no nacional, discute-se os resultados encontrados apontando para uma favorável adaptação ao novo contexto social, nos dois grupos.

Porém, antes de discutir os resultados, cabe explicar que o uso de ex-atletas não comprometeu os resultados, já que foi suportado pela literatura ${ }^{34,35}$. Somado a isso, a expatriação nacional é algo importante para o estudo, pois PISANI ${ }^{10}$ afirma que expatriação é um processo que envolve mudança de país, estado ou cidade com o intuito de trabalhar, estudar ou jogar, ou seja, a expatriação no mesmo país é algo que ocorre e, assim, deve-se investigar o processo de adaptação ao novo contexto social de atletas que são expostos a tal expatriaçáo.

Retomando o objetivo do estudo, os resultados apontaram para um convívio amistoso, positivo e sem complicaçôes para os atletas do grupo G1. Essa informação foi suportada pelos resultados, pois a média para as diferenças religiosas foi baixa $(1,60)$ e a média para o uso de serviços foi moderada $(3,90)$. Os resultados sugerem que a diferença religiosa não foi problema para os atletas e que tiveram facilidade com os serviços do novo país, pois conseguiram utilizar adequadamente os supermercados, os quais atenderam de forma satisfatória às expectativas do atleta.

Outro indicativo de boa adaptação, para o grupo G1, diz respeito às novas amizades que o atleta adquiriu dentro e fora do clube e os novos lugares que conheceu. Os resultados frente a esses itens demonstraram que os atletas do grupo G1 tiveram uma vida social satisfatória no novo país, já que fizeram novas amizades, se relacionaram com os nativos de forma amistosa e conheceram novos lugares. Essas novas amizades e o bom relacionamento com os nativos deram ao atleta do grupo G1 a percepção de ser respeitado no novo país, levando-o a ter mais disposição para conhecer novos lugares, já que não se sentia discriminado. Tais resultados refutam alguns achados da literatura que apontam para dificuldades de adaptação às normas e a nova cultura na adaptação do expatriado ao novo país ${ }^{9,13,26}$.

Possivelmente esses resultados devem-se em função dos atletas "cultivarem" uma vida social extra clube, o que favoreceu a adaptação ao novo ambiente social. Tal hipótese é sustentada pela literatura, a qual aponta que o isolamento social é um fator relevante na dificuldade de adaptação ao novo contexto social ${ }^{27}$. Assim, o isolamento leva o atleta a uma sensaçáo de distanciamento da cultura de origem e dificulta a adaptação do atleta a nova cultura ${ }^{20}$, o que não ocorreu no presente estudo, haja vista os resultados apontarem para o efeito contrário, ou seja, os atletas não se isolaram do novo ambiente e com isso não sentiram o rompimento com a cultura de origem. Em outras palavras, não houve uma brusca troca de realidade, ou se houve, o atleta foi capaz de lidar com tal mudança de forma adequada, adaptandose ao novo contexto social ${ }^{21,28}$.

Os resultados do grupo G2, sobre o convívio na nova cidade com a população, apontaram para um convívio amistoso, positivo e sem complicaçóes para os atletas, pois a média para as diferenças religiosas foi de moderada para baixa $(2,34)$ e a média para o uso de serviços também foi moderada $(3,66)$. Aliadas a esses valores médios, as análises inferenciais demonstraram que diferença religiosa, discriminação e falta da família tiveram valores inferiores aos valores dos itens que dizem respeito a boa adaptação social. Em relação à discriminação, o fato de estarem dentro do próprio país e de serem do Sul e Sudeste, a grande maioria, pode ter contribuído 
para os baixos resultados. Em síntese, os resultados demonstram que os participantes souberam lidar com essa diferença religiosa e utilizar adequadamente os serviços oferecidos na cidade.

De acordo com Holopainen e BJörKMAN ${ }^{36}$, para que o expatriado tenha sucesso na expatriaçáo deve ter habilidade para comunicação, independente de dominar o idioma local. Além disso, o expatriado que apresentar experiência de expatriação tende a ter mais sucesso no processo. E mais, os expatriados devem passar por treinamentos acerca da cultura do novo país, para ajudá-los na percepção dessa mudança ${ }^{13,21}$. Neste estudo, dados os resultados positivos do processo de expatriação, parece que os atletas não tiveram problemas com o idioma local.

Em relação aos atletas nacionais isso era esperado, pois eles se deslocaram dentro do Brasil. No caso dos atletas internacionais, o que pode explicar os resultados, é o fato do destino de maior procura de atletas ser Portugal (30\% dos participantes), contribuindo para o domínio da língua. De acordo com SousA ${ }^{37}$, a fluência da língua nativa, por parte do expatriado, é um elemento que facilita o processo de adaptação intercultural, o que pode ter grande relação com os resultados do presente estudo, já que a maior parte dos expatriados internacionais foram para Portugal, corroborando o estudo de Pontes et al. ${ }^{29}$, no qual os autores apontam que a adaptação é facilitada quando o expatriado domina o idioma local.

Os resultados desse estudo sugerem que os atletas do grupo internacional passaram por menores problemas de discriminação do que os resultados apontados na literatura, ${ }^{9,34}$, demonstrando maior capacidade de adaptação dos atletas deste estudo. Provavelmente o fato de a maioria dos atletas internacionais terem ido para Portugal, pode ter contribuído para esses resultados positivos de adaptação e menor discriminação. De acordo com Machado e Hernandes $^{7}$, o expatriado pode se deparar com situaçóes de confronto de sua cultura com outras culturas, ocasionando no expatriado um conflito psicológico, decorrente da dificuldade em reconhecer a outra cultura. Nessa relação com a nova cultura, o expatriado constrói a visão de si mesmo, contribuindo com a construção da identidade e da compreensáo da diferenciaçáo com o outro ${ }^{20,21,27,28}$.

Diante disso, a inserção do expatriado na sociedade, no que diz respeito ao convívio social, acontece pelas identificações e pelas diferenciaçóes, estabelecendo fronteiras psicológicas entre os limites pessoais e dos nativos ${ }^{7,21}$. Além disso, existe a necessidade de interação social dos indivíduos, o que se deu, nesse estudo, pela vinculação dos expatriados com diferentes grupos (os atletas do novo clube e os nativos), fornecendo sentido a sua estada na nova cidade (nacionais) ou no novo país (internacionais), corroborando a literatura ${ }^{13}$ para uma adequada adaptação do atleta ao novo ambiente. Essa interação foi reforçada pelos resultados do estudo, os quais apontaram para um bom relacionamento do expatriado com os nativos, além do expatriado aproveitar sua estada no novo pais (grupo internacional) para visitar novos lugares. Além disso, o convívio na nova cidade pode ter sido facilitado pela relaçáo positiva que o atleta construiu com a torcida. De acordo com Schiavon et al..$^{38}$, a torcida exerce pressão positiva ou negativa no atleta e em sua equipe e com isso influencia diretamente o comportamento do atleta. Todavia essa variável não foi avaliada no presente estudo, servindo apenas como uma possível explicação para os resultados.

Em relaçáo aos atletas internacionais, o convívio com os nativos, facilitou o processo de confronto frente à nova cultura ${ }^{27}$, haja vista os resultados sugerirem que não houve dificuldade, por parte do expatriado em reconhecer a outra cultura, construindo, assim, uma identidade e compreensão da cultura do novo país e uma relaçáo amistosa com os nativos. Referente aos atletas nacionais, a mesma construção de discussão pode ser tomada como explicação para os resultados apresentados nesse estudo, frente à adaptação à nova cidade. A identidade dos atletas nacionais foi construída frente a essas identificações e diferenciações, estabelecendo fronteiras psicológicas entre os limites pessoais e dos nativos ${ }^{7}$, nesse caso, entre os limites pessoais e os limites das pessoas da nova cidade.

Concernente ao grupo internacional, a religião náo foi um fator que atrapalhou sua adaptação ao novo país, possivelmente por esses atletas terem conseguido processar as identificaçóes e diferenciaçôes. O fato de, em ambos os grupos, a religião não ter sido um fator determinante para prejudicar a adaptação ao novo contexto (cidade ou país) pode ser entendido como controle emocional ${ }^{13}$. De 
acordo com Epelboim ${ }^{39}$, as diferenças entre as religiōes são motivadas pelas emoçôes, e que essas emoçóes sustentam a fé. Nesse caso, os resultados desse estudo demonstram que os atletas, possivelmente, controlaram suas emoçôes frente às adversidades religiosas.

Sobre conhecer novos lugares, para o grupo internacional, isso pode ter relação com a fase de lua de mel, proposta por Black, Mendenhall e $\mathrm{ODDOU}^{40}$ na teoria da curva em U do ajustamento intercultural. De acordo com a teoria, as pessoas expatriadas, no primeiro momento, se encantam com as novidades do novo país e sua cultura, querendo conhecer o novo país e a nova cultura. Neste estudo, os resultados sugerem que os atletas se encantaram com o novo país e com a nova cultura, desfrutando da interação com essa novidade e, com isso, visitando novos lugares e aceitando a cultura local.

Concernente à fase de choque cultural da teoria, parece que os atletas não sentiram essa fase em condições de atrapalhar a adaptação ao novo país, pois os resultados não demonstraram desconforto ou rejeição à nova cultura. Esse resultado pode ter grande relação com o bom convívio que o atleta estabeleceu dentro do clube, o que contribuiu para controle do choque cultural $^{21}$, assim como com o fato dos atletas permaneceram mais de um ano no novo país (60\% dos participantes).

Além disso, os resultados sugerem que os atletas tiveram integração com a nova cultura ${ }^{41}$, o que contribuiu para o não desconforto frente ao convívio com os nativos, corroborando os resultados de outros estudos $8,9,34,42,43$. Esse bom convívio com a cultura local é fundamental para a adaptação do expatriado, pois ele se sente recebido com hospitalidade e respeito e, mais do que isso, tal relação demonstra respeito mútuo entre o expatriado e os nativos ${ }^{34}$, o que pode ser entendido como um pilar necessário para uma boa adaptação.

Em relação ao grupo nacional, os resultados apresentaram um convívio extra clube adequado, muito influenciado pelos serviços oferecidos na cidade, demonstrando que as facilidades de serviços oferecidos pelas cidades foram importantes para a adaptaçáo à nova cidade. Esses resultados representam um processo de adaptação à expatriação muito parecido com o processo de adaptaçáo à expatriação do grupo internacional. Além disso, o choque cultural esperado no grupo internacional náo era esperado no grupo nacional, já que os atletas migraram dentro do próprio país e entre regióes próximas, o que favoreceria a adaptação do atleta, e essa hipótese foi confirmada pelos resultados de adaptação à nova cidade.

Mediante o conjunto de resultados, em relação a adaptação dos participantes (G1 e G2), houve interaçáo entre os participantes e o novo contexto social. Sendo assim, a interação entre os participantes e o contexto social foi mais que uma simples interação, ela significou a construçâo de um significado relacional ${ }^{44}$. Essa relação levou o atleta a construir novas amizades e, com isso, ter um bom convívio, o que contribuiu com sua adaptação ao novo contexto social.

Todo esse conjunto de competências do atleta utilizadas para se adaptar à circunstância adversa da expatriação é conhecido por estratégias de confronto ou coping. Coping é um conjunto de estratégias utilizadas, pelas pessoas, para se adaptarem a circunstâncias adversas e lidar de forma eficiente com essas situaçóes, muitas vezes estressoras ${ }^{45}$. Frente aos resultados, os atletas do grupo internacional demonstraram ajustamento intercultural, ou seja, habilidade em se adaptar ao novo ambiente cultural de modo eficiente e suficientemente confortável ${ }^{16,46}$.

Diante disso, os resultados do estudo, acerca da adaptação dos atletas ao novo contexto, para ambos os grupos, sugerem que os atletas se utilizaram de estratégias de coping para se adaptarem às circunstâncias adversas. Mais do que isso, os resultados sugerem que a estratégia de coping, possivelmente utilizada pelos atletas, foi a de coping ativo, sobretudo, com foco no esforço e trabalho e o confronto com a adversidade ${ }^{47,48}$.

Outro fator que pode ter contribuído para a boa adaptação dos atletas ao novo clube, é o fato de terem se profissionalizado. Os estudos demonstram que atletas profissionais são mais confiantes e motivados em ultrapassar quaisquer barreiras durante a prática esportiva ${ }^{27,49}$. Somado a isso, a literatura aponta para uma perspectiva de adaptação ao novo contexto social os atletas que apresentam um bom nível de instrução formal (escolar) e bom nível técnico no esporte ${ }^{27}$.

Como no presente estudo os atletas investigados eram profissionais, o bom nível técnico pode ser um fator explicativo, também, 
da boa adaptação ao processo de inserção na nova cultura. Evans e TEAAD $^{27}$ apontam que os atletas com maior nível técnico conseguem estabelecer relaçóes interpessoais mais saudáveis e positivas, o que contribui para uma melhor adaptação ao novo contexto social.

De acordo com OliveirA ${ }^{49}$, os atletas profissionais apresentam estratégias de coping melhor definidas do que os atletas amadores, assim conseguem enfrentar situaçóes estressantes de forma a não atrapalhar seu rendimento, além de formularem melhor seus objetivo, o que faz com que sejam mais confiantes para enfrentarem as adversidades. Oliveira ${ }^{49}$ sugere que atletas mais velhos lidam melhor com situaçóes estressantes. Como neste estudo a amostra internacional foi composta de atletas profissionais e com medida de idade acima de 30 anos, é possível utilizar a explicação de Oliveira ${ }^{49}$ para corroborar os resultados do presente estudo para o grupo internacional.

Considerando o objetivo do presente estudo, os dados demonstraram que os atletas dos dois grupos apresentaram comportamentos de adaptação ao novo contexto social parecidos, como, por exemplo, o uso de serviços da cidade. Assim, os atletas demonstraram desenvolvimento dos recursos pessoais relacionados à demanda do contexto ${ }^{16}$. Alguns mecanismos pessoais foram fundamentais para manutenção, aprimoramento e correção das competências e recursos motivacionais após a expatriação. Isso é suportado pelos resultados deste estudo que, demonstram que os atletas tiveram uma adaptação positiva ao novo contexto social, além de demonstrarem facilidade de adaptação as diferenças religiosas e a utilização dos serviços disponíveis nas cidades e países. Tais fatos levaram os atletas a terem uma vida social ativa, saindo, passeando e conhecendo novos lugares e pessoas, corroborando a literatura, a qual aponta que a adaptação do atleta tem relação com o não isolamento do mesmo ${ }^{9,13,20}$.

Finalizando, o manuscrito, apoiado em seus resultados e em Pereira et al. ${ }^{41}$, sugere-se que a adaptaçáo ao novo contexto social está relacionada com as capacidades de enfrentamento que os atletas demonstram, assim como a boa receptividade dos nativos. Dessa forma, dependendo do local em que o atleta irá, sugere-se o acompanhado de um treinamento para facilitação do ajustamento intercultural ${ }^{13,16,21}$.

No que diz respeito ao treinamento intercultural, o papel da família no processo de adaptação e no sucesso da expatriação é essencial, haja visa os resultados frente o papel da família na adaptaçáo do atleta ao novo contexto social ${ }^{8,9,11,16,23-25,34}$. Para que isso ocorra com todos os atletas, deve-se estabelecer modelos em que a família esteja envolvida, tanto no treinamento, quanto na expatriação propriamente dita. Isso é relevante para o processo de expatriação, pois a literatura aponta que a família auxilia no processo de expatriaçãa ${ }^{7,11,16,18,37,41,50,51}$. Em síntese, os resultados do presente estudo, assim como os da literatura, sugerem que a adaptaçáo social é facilitada quando o atleta tem a família presente ${ }^{7,9,11,16,18,20,27,37,50,51}$.

A respeito das limitaçōes do estudo, pode-se apontar a náo exploração de informaçóes coletadas com os familiares do atleta sobre a adaptação do participante ao novo contexto social, demonstrando a necessidade de estudos que, além de explorar as informações junto aos atletas, busque informaçôes com os familiares, bem como a influência da família na adaptação. Também, cabe ressaltar que a influência do idioma não foi avaliado, o que pode ser explorado em estudos futuros. Diante disso, sugere-se novos estudos avaliando o papel da família no processo de adaptaçáo ao novo contexto social, a percepção da família sobre a adaptação do atleta ao novo contexto social, a influência do domínio do idioma na adaptação e os benefícios do treinamento intercultural nesse processo, tanto para o Voleibol, quanto para outras modalidades esportivas.

\section{Notas}

a. De acordo com a literatura, os ex-atletas, mesmo não vivenciando mais os esporte, são capazes de comentar sobre como enfrentaram essas adversidades ao longo da carreira e os resultados dessas vivências ao longo do tempo ${ }^{34,35}$.

b. A plataforma do Google Formulários ${ }^{\circledast}$ é uma ferramenta amplamente utilizada, pois o pesquisador não precisa deslocarse até o participantes para realizar a aplicação do questionário ${ }^{32}$, pois o mesmo responde de forma online, além do baixo custo da ferramenta. 


\begin{abstract}
Expatriation and adaptation of volleyball players to the new social context

The purpose of this manuscript was to analyze the adaptation of Volleyball athletes to the new social context, after changing team and city to continue their career, both in the international context and in the national context. Participated 68 people (48 athletes and 20 former athletes), 43 men and 25 women, with a mean age of 27,29 years. Participants were divided into 2 research groups: G1 (International Athletes) and G2 (National Athletes). An instrument was used, with structured questions, which could have open or closed responses with 5-point Likert-type responses. The instrument used was developed and evaluated as evidence of validity via TRI, using the adjustment to the Rasch model. In this manuscript, only the questions pertinent to the purpose of the manuscript were analyzed. For the analyzes between groups, the t-test was used for independent samples and for intra-group analysis, absolute and relative frequency of responses one-way ANOVA, dependent t-test and Pearson's correlation. The results showed that both groups showed good adaptation to the new social context, greatly influenced by the ease of services offered by cities and non-discrimination. In addition, the participants of the two groups were able to form new friends, which facilitated their conviviality in the new social context, outings and extra-club relations. In view of these results, it can be concluded that the participants of this study demonstrated adequate personal resources to adapt to the context changes, quite possibly because they used coping strategies for this social confrontation.
\end{abstract}

KEYwORDS: Sports Psychology; Expatriation; Volleyball; Social context; Adaptation.

\title{
Referências
}

1. Tanure B, Evans P, Pucik V. Virtudes e pecados capitais: a gestáo de pessoas no Brasil. Rio de Janeiro: Elsevier; 2007.

2. Adler NJ. Women in international management: where are They? Calif Manage Rev. 1984;26(4):78-89.

3. Certo S. Administração Moderna. São Paulo: Makron Books; 1997.

4. Bonache J. "La Gestión de Expatriados.” In: Times F, Bonache J, Cabrera Á, editors. Dirección estratégica de personas. Madrid: Prentice Hall; 2002. p. 479-398.

5. Gallon S, Antunes EDD. Processo de Expatriação: um modelo com fases e práticas. Rev Eetrônica Estratégia Negócios. 2015;8(2):54-84.

6. Zwielewski G. Desafios da Expatriação [Internet]. Rev Fator Brasil. 2009 [citado 5 jul 2016]. Disponível em: http:// www.revistafatorbrasil.com.br/ver_noticia.php?not=83185

7. Machado HV, Hernandes CA. Alteridade, expatriação e trabalho: implicações para a gestão organizacional. Rev Adm Contemp. 2004;8(3):53-73.

8. Brandão MRF, Magnani A, Tega E, Medina JP. Além da cultura nacional: o expatriado no futebol. Rev Bras Ciência e Mov. 2013;21(2):177-82.

9. Faggiani FT, Strey A, Fuginiti D, Lindern D, Aiquel PF, Sartori C. O Fenômeno do expatriado no contexto esportivo. Psicol Ciência e Profissão. 2016;36(3):738-47.

10. Pisani MS. Migraçóes e deslocamentos de jogadoras de futebol: mercadoria que ninguém compra? Esporte Soc. 2014;9(23):1-11.

11. Tertuliano IW. Processo de expatriação de voleibolistas: Concepçôes Bioecológicas. [Tese]. Rio Claro: Universidade Estadual Paulista; 2016.

12. Tiesler NC. Three types of transnational players: differing women's football mobility projects in core and developing countries. Rev Bras Ciências Esporte. 2016;38(2):201-10.

13. Agergaard S, Ryba T V. Migration and career transitions in professional sports: transnational athletic careers in a psychological and sociological perspective. Sociol Sport J. 2014;31(2):228-47.

14. Teixeira F. Expatriados Futebol Clube. Belo Horizonte: Editora do autor; 2014.

15. Fontes AC. A vida nômade de atletas que vestem camisas de vários times pelo mundo [internet]. Globoesporte.com.

Rev Bras Educ Fís Esporte, (São Paulo) 2021 Jul-Set;35(3):27-41 • 39 
Rio de Janeiro; 2011 [citado 17 mai 2015]. Disponível em: http://globoesporte.globo.com/eventos/futebol-de-areia/ noticia/2011/07/vida-nomade-de-atletas-que-vestem-camisas-de-varios-times-pelo-mundo.html

16. Tertuliano IW, Oliveira V, Bartholomeu D, Ribeiro LB, Montiel JM, Machado AA. Motivos que levam os voleibolista a retornarem ao Brasil após a expatriação. Rev Bras Educ Física Esporte. 2019;33(1):85-98.

17. Prestes VA, Grisci CLI. Autoexpatriação: uma compreensão à luz dos movimentos de territorialização, desterritorialização e reterritorialização. In: IX Congresso Brasileiro de Estudos Organizacionais. Porto Alegre; 2016.

18. Stahl GK, Miller EL, Tung RL. Toward a boundaryless career: a closer look at the expatriate career concept and the perceived implications of an international assignment. J World Bus. 2002;37:216-27.

19. Rigo LC, Silva D V., Rial CSM. Formação de jogadores em clubes de uma cidade do interior: circulação, escolarização e inserção no Futebol profissional. Movimento. 2018;24(1):263-74.

20. Richardson D, Littlewood M, Nesti M, Benstead L. An examination of the migratory transition of elite young European soccer players to the english premier league. J Sport Sci. 2012;30(15):1605-18.

21. Tibbert SJ, Andersen MB, Morris T. What a difference a "Mentally Toughening" year makes: the acculturation of a rookie. Psychol Sport Exerc. 2015;17:68-78.

22. Weedon G. "Glocal boys": exploring experiences of acculturation amongst migrant youth footballers in premier league academies. Int Rev Sociol Sport. 2011;47(2):200-16.

23. Rodrigues FXF. O fim do passe e as transferências de jogadores brasileiros em uma época de globalização. Sociologias. 2010;12(24):338-80.

24. Machado FS. Gestão de pessoas interncional no contexto esportivo brasileiro: uma análise dos processos de expatriação e repatriação de jogadores em um clube de futebol gaúcho. [Dissertação]. Porto Alegre: Universidade Federal do Rio Grande do Sul; 2013.

25. Rial C. Rodar: a circulação dos jogadores de futebol brasileiros no exterior. Horizontes Antropológicos. 2008;14(30):21-

65.

26. Agergaard S. Elite athletes as migrants in Danish women's handball. Int Rev Sociol Sport. 2008;43(1):5-19.

27. Evans AB, Stead DE. "It's long way to the super league": the experiences of Australisian professional rugby league migrants in the United Kingdon. Int Rev Sociol Sport. 2014;49:707-27.

28. Schinke RJ, McGannon KR, Battochio RC, Wells GD. Acculturation in elite sport: a thematic analysis of immigrant athletes and coaches. J Sports Sci. 2013;31(15):1676-86.

29. Pontes VS, Ribeiro CHV, Garcia RM, Pereira EGB. Migração no Voleibol brasileiro: a perspectiva de atletas e treinadores de alto rendimento. Movimento. 2018;24(1):187-98.

30. Sebben A. O preparo do atleta de futebol [Internet]. Universidade do Futebol. 2009 [citado 17 mai 2015]. Disponível em: http://universidadedofutebol.com.br/andrea-sebben-psicologa-parte-1/

31. Confederação Brasileira de Voleibol. CBV [Internet]. 2015 [citado 17 mai 2015]. Disponível em: http://www.cbv.com.br

32. Kozinets R V. Netnografia: realizando pesquisa etnográfica online. Porto Alegre: Penso; 2014.203 p.

33. Green SB, Salkind NJ, Akey TM. Using SPSS for windows: analyzing and understanding data. 2nd ed. New Jersey: Prentice Hall; 2000.

34. Freitas LPR, Costa Neto JR, Cardoso RM, Ferreira MPP. Estudo do fenômeno do regresso de ex-atletas sul-mineiros de futebol do exterior. Lect Educ Física Deport. 2012;16(164):1-9.

35. Fontes RCC, Brandão MRF. A resiliência no âmbito esportivo: Uma perspectiva bioecológica do desenvolvimento humano. Motriz. 2013;19(1):151-9.

36. Holopainen J, Björkman I. The personal characteristics of the successful expatriate. Pers Rev. 2005;34(1):37-50.

37. Sousa AFB. A adaptação intercultural da família: um estudo exploratório com expatriados portugueses. [Dissertação]. Vila do Conde: Instituto Politécnico do Porto; 2014.

38. Schiavon MK, Fischer F, Machado AA, Verzani RH, Gouvea FC. Percepção dos atletas de Voleibol sobre a influência da torcida. Coleção Pesqui em Educ Física. 2010;9(2):203-8.

39. Epelboim S. Identidade judaica: consideraçôes psicológicas acerca da dimensão religiosa. Estud Psicol. 2006 Mar;23(1):47-54.

40. Black SJ, Mendenhall M, Oddou G. Toward a comprehensive model of international adjustment: an integration of multiple theoretical perspectives. Acad Manag Rev. 1991;16(2):291-317.

41. Pereira NAF, Pimentel R, Kato HT. Expatriação e estratégia internacional: o papel da família como fator de equilíbrio na adaptação do expatriado. Rev Adm Contemp. 2005;9(4):53-71.

42. Gullahorn JT, Gullahorn JE. An extension of the U-curve hypothesis. J Soc Issues. 1963;19:33-47. 
43. Chang YC. Cross-Cultural adjustment of expatriates: on american and japanese expatriates. Seoul J Bus. 1997;3(1):14767.

44. Lazarus RS. Emotion and adaptation. New York: Oxford University Press; 1991.

45. Antoniazzi AS, Dell'Aglio DD, Bandeira DR. O conceito de coping: uma revisão teórica. Estud Psicol. 1998;3(2):194273.

46. Black JS, Mendenhall M. Cross-cultural training effectiveness: a review and theoretical framework for future research. Acad Manag Rev. 1990;15(1):113-36.

47. Vieira LF, Carruzo NM, Aizava PVS, Rigoni PAG. Análise da síndrome de "burnout" e das estratégias de "coping” em atletas brasileiros de vôlei de praia. Rev Bras Educ Física Esporte. 2013;27(2):269-76.

48. Ribeiro R, Dias C, Cruz JF, Corte-Real N, Fonseca A. Avaliações cognitivas, emoçóes e coping: um estudo com futebolistas portugueses. Rev Iberoam Psicol Ejerc Deport. 2014;9(1):191-207.

49. Oliveira LP. Motivação, estratégias de coping e perfeccionismo em atletas profissionalizados e não profissionalizados de futebol de campo. [Dissertação]. Maringá: Universidade Estadual de Maringá; 2009.

50. Carvalho SMS. A relação entre a gestão da carreira e a expatriação: um estudo quantitativo com repatriados portugueses. [Dissertação]. Vila do Conde: Instituto Politécnico do Porto; 2016.

51. Tung RL. American expatriates abroad: From neophytes to cosmopolitans. J World Bus. 1998;33(2):125-44.

\begin{tabular}{r|l} 
ENDEREÇO & \\
Ivan Wallan Tertuliano & Submetido: 16/03/2018 \\
Universidade Anhembi Morumbi & Revisado: 06/07/2018 \\
Rua Dr. Almeida Lima, 1.134 - Mooca & Aceito: 07/10/2020 \\
03164-0oo - São Paulo - SP - Brasil & \\
E-mail: ivanwallan@gmail.com & \\
&
\end{tabular}

